\title{
A personagem e seu mundo: uma análise de $A$ moratória, de Jorge Andrade
}

\author{
Larissa de Oliveira NEVES ${ }^{1}$ \\ Universidade Estadual de Campinas - Unicamp
}

O objetivo do presente artigo consiste em examinar a individualidade das personagens de $A$ moratória, de Jorge Andrade, de modo a demonstrar sua complexidade literária, que vai além de sua adequação ao contexto histórico e cultural brasileiro retratado. Para tanto, optei por realizar uma análise comparada entre a peça e O jardim das cerejeiras, de Anton Tchekhov. Diversos críticos têm apontado e analisado detidamente o quanto $A$ moratória, à semelhança das demais obras de Jorge Andrade reunidas no volume Marta, a árvore e o relógio, representa exemplarmente um momento único e importantíssimo dentro de nossa história, seja social, política ou econômica (Cf. ARANTES, 2001; SANT'ANNA, 1997).

De fato, como bem mencionou Décio de Almeida Prado (1970, p. 626):

Não compreenderá nada do alcance da peça quem não pressentir, por trás dos indivíduos e dos episódios particulares que ela narra, a agonia de uma sociedade em vias de transição, aquela dolorosa passagem do Brasil dos fazendeiros para o Brasil urbano tão bem descrita por Gilberto Freyre.

A maneira representativa como a obra insere em sua temática o desmoronamento de um modo de vida rural e patriarcal, especificamente brasileiro, não impede, porém, que se observe como a construção das personagens propicia ao leitor

\footnotetext{
1 Professora doutora e pesquisadora de teatro, leciona no curso de Artes Cênicas, da Unicamp. Coordenadora e membro fundador do grupo de pesquisa: Grupo de Estudos em Dramaturgia Letra e Ato. E-mail: larissadeoneves@gmail.com.
} 
uma identificação que extrapola o nível do regionalismo e atinge uma sensibilidade comum ao ser humano em geral.

Já disse Jorge Andrade (1978, p. 34), em seu romance autobiográfico Labirinto: "O homem é sempre o mesmo, que as paixões não variam em São Paulo, Piauí, Estados Unidos ou África. É sempre o homem diante da terra, da mulher, do espaço, do suor, do amor, de crenças ou temores". Afinal, estamos diante de uma obra de arte e uma das diferenças entre a arte e a historiografia consiste exatamente na capacidade de emocionar, de falar intensamente sobre os sentimentos do homem, independentemente do local ou do tempo em que vive.

O próprio Décio de Almeida Prado conclui seu artigo com essa constatação, ao narrar uma anedota de cunho particular, em que descreve uma viagem aos Estados Unidos, na qual, para sua surpresa, deparou com um grupo de estudantes universitários a ensaiar a peça. Aos poucos, relata o crítico, "coisas como moratória, colheita de café, ponto de goiabada, que unicamente nós, brasileiros, julgaríamos entender" foram se transformando, pela "emoção dos atores" que "foi ganhando a sala, estendendose aos raros circunstantes", de modo que

aquele mundo restrito que eu conhecera menino havia se transformado em símbolo universal e falava com igual persuasão numa língua estrangeira. A moratória, que eu julgava possuir quase uma lembrança de família, fugira de mim e se instalara num território estranho e cheio de prodígios, - aquele em que comungamos, por exemplo, com um pequeno grupo de aristocratas russos que tentam em vão preservar contra o machado destruidor o seu querido e já irremediavelmente perdido jardim de cerejeiras (PRADO, Op. cit., p. 629).

Transcrevo todo o trecho porque o presente estudo ganha corpo a partir das afirmações de Décio de Almeida Prado registradas no curto, porém revelador, artigo em que analisa a peça. Meu intuito consiste em ampliar, na medida das possibilidades de espaço, as ideias lançadas acima, a partir de um exame das personagens que evoque um entendimento 
psicológico, a fim de investigar a criação literária capaz de, pelo regional, atingir o universal. Nesse sentido, a comparação fugaz realizada por Almeida Prado na conclusão de seu texto mostra ser uma ferramenta bastante útil, já que as aproximações entre $A$ moratória e $O$ jardim das cerejeiras permitem um desmembramento abrangente referente às potencialidades emotivas da trama andradiana.

As semelhanças entre Joaquim, de A moratória, o patriarca cuja vida perde todo o sentido quando se vê afastado de sua fazenda, e Liubov Andreievna, de $O$ jardim das cerejeiras, a proprietária de terras russa que também sofre com a perda de suas terras, consistem em fortes indicativos do quanto a arte possibilita uma aproximação entre dois mundos aparentemente tão distantes quanto a Rússia da virada do século (XIX - XX) e o Brasil do começo da década de 1930. E essa proximidade possibilita realizar a constatação da mestria com que Jorge Andrade criou suas personagens, a ponto delas alcançarem representar sentimentos que suscitam a identificação, inclusive, daqueles que não compartilham do mesmo meio cultural, daqueles que, como bem escreveu Décio de Almeida Prado, não sabem o que significa "ponto de goiabada".

Ambas as peças tratam da desagregação de todo um sistema social, e do nascimento de um outro, mais democrático, em que os antigos padrões de cultura, de classe, se não perderam a importância, ao menos se transformaram. Surgem novos valores aos quais as pessoas precisam se adaptar. Se para os jovens a adaptação pode gerar, no caso positivo, um sentimento de esperança, no negativo, de resignação; para os velhos a mudança significa um grande sentimento de desilusão, de incompatibilidade, de desentendimento.

Joaquim e Liubov são velhos que fazem parte de um mundo que se arruína. Vêem, impotentes, o modo de vida ao qual dedicaram suas existências se despedaçar diante de seus olhos. Lutam como podem para mantê-lo, em vão. Sonhadores, não 
conseguem encarar a realidade e permanecem durante $\mathrm{O}$ desenvolvimento dos enredos na ilusão de um possível retorno, no caso de Quim, ou de manter seu jardim, no caso de Luibov, para, ao final, serem obrigados a confrontar tragicamente $\mathrm{o}$ desfecho fatídico. Não há retorno.

A perda das fazendas, em ambas as peças, configura não somente uma transformação econômica na vida de seus donos, mas uma radical mudança de referência. Tudo que era dado como certo não existe mais: as personagens ficam sem chão. $\mathrm{O}$ que de fato sensibiliza o público, em ambos os textos teatrais, não são os acontecimentos reais que marcaram a passagem do Brasil e da Rússia para uma nova etapa histórica, e sim a identificação que o sentimento de perda irremediável de algo importante desperta. Mesmo que o espectador nunca tenha sofrido uma privação tão definitiva, a profundidade com que os caracteres são construídos permite que se entre em comunhão com aqueles sentimentos extremos vivenciados por elas de maneira tão verossímil.

Em A moratória temos o privilégio de observar Quim em dois momentos: pouco antes de sair da fazenda e, já na cidade, quando busca recuperá-la. Esses momentos são separados pela distância temporal dos dois planos. De um lado se apresenta a vida tal qual mantinha na fazenda, em 1929; de outro, a esperança do retorno e o novo cotidiano na cidade, repleto de dificuldades, não só de adaptação, mas também econômicas.

Em O jardim das cerejeiras misturam-se as duas situações, já que presenciamos os últimos dias de vida no campo em concomitância com os esforços da família para manter suas terras. Apesar de algumas indicações nos diálogos, não nos é revelado o modo como esta seguirá adiante após a despedida de seu jardim. Assim, a esperança é o sentimento que prevalece, mesmo ao final, embora sem conseguir velar a melancolia que toma conta de Liubov e de seu irmão Gaiev. Os jovens, no entanto, estão felizes; eles visualizam um futuro radiante e novo, enquanto os velhos 
choram. Essa é a maior diferença entre os dois textos, que abarca temática e estrutura.

Se existe a possibilidade de $O$ jardim das cerejeiras ser considerada uma comédia, como o fez o seu autor (Cf. TAKEDA, 2003), - devido à estrutura, que apresenta diversos recursos cômicos, embora esses permaneçam velados pela temática nada engraçada; e perspectiva positiva emanada do desfecho -, em $A$ moratória essa possibilidade não existe. Nela, o futuro nos é revelado. Sabemos como a família de fazendeiros reconstruiu sua rotina na cidade. Daí a tragicidade da obra brasileira ser mais dominante. Aqui, os jovens não são felizes, não conseguiram se adaptar ao modo de vida urbano. Os velhos menos ainda. A esperança que existe é a do retorno à vida antiga, não a de uma vida melhor no futuro. Quando essa esperança se mostra infundada, no final da peça, nada mais resta, para ninguém.

Joaquim surge aos nossos olhos, no começo do texto e no plano da cidade, como um velho senhor que não tem absolutamente nada para fazer, por isso rodeia sua filha, Lucília, enquanto esta trabalha freneticamente numa máquina de costurar. Ele atrapalha o andamento do trabalho de Lucília, que, pacientemente, procura responder à conversação, porque tem consciência do sofrimento do pai. Pouco depois, ele aparece no plano da fazenda, três anos antes: um outro homem, senhor de sua casa, ativo, trabalhador, vestindo uma roupa de trabalho no campo. O contraste ajuda a revelar o caráter da personagem, que se manifesta por meio de diálogos simples, envolvendo não somente o tema central da perda das terras, mas também, e talvez fundamentalmente, assuntos do cotidiano da família.

Essa maneira de revelar por meio da simplicidade, do nãoimportante, dos pequenos diálogos cotidianos que, quando reunidos no todo do texto, demonstram refletir a complexidade de cada indivíduo, consiste num ponto estilístico comum a Jorge Andrade e Anton Tchekhov. Além de Décio de Almeida Prado, 
outros críticos apontaram a semelhança, embora nenhum tenha realizado uma análise mais detida. Juvenal de Souza Neto, num dos primeiros trabalhos acadêmicos efetuados sobre o autor, dedicou uma parte de sua dissertação a tratar das semelhanças com a obra do dramaturgo russo. No entanto, a comparação não chega a ser vertical, detendo-se, principalmente numa comparação entre Liubov e Norma, de Senhora na boca lixo.

Tchekhov possui, como Jorge Andrade, a habilidade de humanizar suas personagens, que não se tornam caricaturas nem esquematizações passíveis de redução ideológica ou psicológica. É o caso de Joaquim, Noêmia e Liuba, sendo as duas, sobretudo a última, modelos de generosidade próprios da postura de superioridade típica de aristocratas. O drama dos três comove pelo abandono do que possuem de mais querido e que, no caso de Joaquim, é quase fatal. Não são personagens que provocam antipatia e sim compreensão e comoção. (SOUZA NETO, 1987, p. 57)

As personagens, tanto as andradinas como as thekhovianas, são moldadas com tamanha veracidade e carinho que comovem o leitor/espectador. Cada uma delas, mesmo a mais mesquinha, é capaz de ser compreendida como um ser humano real, com qualidades e defeitos. Assim, embora sejam expostas com veracidade as fraquezas e imperfeições de cada personagem, a "compreensão afetuosa" dos escritores para com suas criações atinge o receptor da obra. Ilka Marinho Zanotto (apud ALBISSU, 1997, p. 54) constatou essa semelhança entre os dramaturgos:

A compreensão afetuosa com a qual encarou seus personagens, mesmo quando avaliados criticamente, dá aos seus textos uma aura inequivocamente checoviana, porque povoados de gente inadaptada às exigências do presente, apegada ao mundo em extinção que Jorge Andrade resgatou como ninguém das neblinas da memória.

Quim consiste na personagem símbolo desse apego a um "mundo em extinção", cuja personalidade delineia-se pouco a 
pouco diante do espectador. Suas falas, ligadas ao prosaico, ao dia a dia da fazenda, à sua relação com a esposa e os filhos demonstram, de maneira fragmentada, a complexidade de sua personalidade, cinzelada cuidadosamente pelo autor, à maneira de Tchekhov.

No plano da fazenda, ele é o patriarca, acostumado a trabalhar ao ar livre desde o nascer do sol e a ver suas ordens serem obedecidas, inclusive, e talvez principalmente, pelos membros da família. Essa característica de homem forte, porém, não é exposta imediatamente ao público. Jorge Andrade parte, primeiramente, da posição de humildade diante de sua filha, apresentada no plano da cidade, para então mostrar a arrogância, nos tempos de fazendeiro.

Esse recurso (a alternância entre os planos) enfatiza não só a mudança de atitude da personagem, mas demonstra a fundo como ela é, de uma forma que não seria alcançada pela exposição direta, ou cronológica, dos fatos. A transformação torna-se evidente em especial no seu relacionamento com Lucília, já que, de moça solteira que deve obedecer às ordens de seu pai, ela passa a ser a chefe da casa, incorporando, pela fatalidade, o papel de provedor, que sempre foi de Joaquim.

São duas as questões por meio das quais, com fina ironia, Jorge Andrade apresenta essa mudança de posição entre pai e filha: o namoro de Olímpio e Lucília, e o trabalho de costura. Enquanto vivem na fazenda, Quim não aceita que a moça aprenda a costurar:

Joaquim - Chega de aprender costura.

Helena - Ela ainda não acabou o curso de dona Marta, Quim!

Joaquim - (Com desprezo) Dona Marta! Uma costureirinha. Bastam algumas noções. A Lucília não vai ser costureira. (ANDRADE, 1970) ${ }^{2}$

2 Todas as citações da peça serão tiradas dessa edição. 
Nem que namore Olímpio, um rapaz burguês e filho de seu maior inimigo político:

Joaquim - Então só porque é advogado pode casar com minha filha?

Helena - É um bom rapaz.

Joaquim - Pelo que vejo, você entregaria nossa filha ao primeiro que aparecesse com um cartucho qualquer de doutor.

Como patriarca, Quim tem autoridade para impor sua vontade sobre a de seus filhos e de sua esposa:

Joaquim - Na minha casa e na minha família mando eu. Sei perfeitamente o que é direito ou não. Sei, também, o que serve para minha filha. Era só o que faltava! Um doutorzinho qualquer mandar em minha filha! Ele que se atreva a... a...

$\mathrm{Na}$ cidade, sua atitude não pode mais ser a mesma. Se por um lado agora é Lucília quem não quer mais se casar, para não impor ao seu marido a carga de sustentar toda a família, por outro é exatamente com as lições de costura que ela consegue não só manter a casa, mas também dar dinheiro ao pai e ao irmão, quando precisam. Olímpio, antes o "doutorzinho que só sabe falar”, torna-se a única fonte de esperança de Quim, já que, como advogado, empenha-se em obter a fazenda de volta, e, como noivo, pode garantir a felicidade de Lucília, felicidade esta que ele, como pai, não poderá mais prover. Além disso, agora é Quim quem procura amolecer o coração da filha, para que aceite o pedido de casamento.

O contraste denuncia a intensa modificação operada na personagem dentro do curto período de três anos. Quim não passa apenas a aceitar o namoro e a insistir no casamento, ou a compreender, embora a contragosto, a importância do trabalho de costureira, ele se torna uma pessoa ociosa e, por isso, envelhece. Sua única motivação, aquilo em que pensa o tempo todo, a razão para continuar vivendo consiste na esperança em retornar ao modo de vida antigo, em recuperar suas terras e voltar 
para a fazenda. Essa expectativa, embora num determinado momento da peça pareça fundamentada pela possibilidade da moratória, não é, de fato, real.

A dificuldade para encarar a realidade da perda aproxima Quim de Liubov Andreievna. A matriarca russa também sustenta até o final a ilusória confiança de que seu jardim se salve. A situação econômica das famílias se equivale, a despeito da distância física, cultural, social dos países a que pertencem. Elas fazem parte de uma aristocracia rural que se estende por várias gerações: foram os donos do poder durante décadas e agora estão ameaçados por uma nova ordem vigente, pelo mundo moderno, do século XX, urbano, que passa a dominar. Sem saber lidar com os novos fatores econômicos, fazem dívidas sobre dívidas, até chegar ao ponto de perder todas as riquezas acumuladas. Vejamos quanto os diálogos se aproximam:

Lucília: Quero saber o que vai acontecer. Diga!

Helena: (Com esforço) Se ele não receber o dinheiro, a fazenda vai à praça.

Lucília: O que é isto?

Helena: Será vendida para pagamento das dívidas.

Ánia: E aqui em casa, quais são as novas? Vocês pagaram os juros?

Vária: Muito longe disso.

Ánia: Meu Deus, meu Deus...

Vária: Em agosto a propriedade será leiloada... (TCHEKHOV , 2003) $^{3}$

Nas duas peças existe uma possibilidade de salvação das terras, caso um membro endinheirado das famílias se compadeça e compre as fazendas. Em $O$ jardim, no entanto, a "tia de Iaroslavl" oferece uma quantia insignificante, que não paga sequer uma parte mínima da dívida. Em $A$ moratória, tia Elvira não arremata as terras e apenas contribui para o sustento da família de Quim com humilhantes porções semanais de leite e café. Por mais que digam compreender o sofrimento dos proprietários rurais, as

${ }^{3}$ Todas as citações da peça são tiradas dessa edição. 
personagens secundárias, no entanto, não conseguem alcançar uma identidade que lhes possibilitem realmente ajudar a diminuir o vazio representado pela mudança radical operada no modo de vida dos protagonistas. Essa característica apresenta-se com mais nitidez em $O$ jardim, porque as personagens externas à família se multiplicam e têm seu lugar no desenvolvimento do enredo. Mas também pode ser visualizada em $A$ moratória, em relação a pessoas da cidade ou de outras classes citadas nos diálogos e especialmente marcada na figura de tia Elvira.

Embora a personalidade de Liubov se diferencie em vários aspectos da de Quim: uma "madame" que viveu na ociosidade, mimada, impulsiva, sempre a esbanjar dinheiro; mesmo consciente das dificuldades econômicas pelas quais passa, não consegue segurar a ânsia de distribuir moedas de ouro indiscriminadamente. $O$ sentimento oriundo da queda dos privilégios de classe torna bastante semelhante o sentimento de cumplicidade que ambas as personagens proporcionam ao leitor/espectador. Elas transmitem ao público uma emoção que supera o pensamento racional invariavelmente experimentado quando pensamos no quanto o mundo ganha quando as riquezas são divididas, quando ocorre uma maior democratização econômica e política.

Diferentemente das personagens que convivem com Quim e Liubov e participam de seu dia a dia, nós, como leitores ou espectadores, podemos partilhar daquele sentimento de infinita perda. Mesmo sendo partidários da opinião de que o mundo caminha rumo à libertação (opinião essa defendida por Jorge Andrade ${ }^{4}$ ), e que a perda de privilégios faz parte desse caminho, a sensibilidade que emana de Joaquim e de Liubov não deixa de nos tocar profundamente, de despertar um sentimento

\footnotetext{
4 "Acredito imensamente na história, no processo histórico, concluindo disso que o homem irá alcançar seu momento de libertação social e existencial, apesar de viver mesmo com todas as suas contradições" (ANDRADE apud SANT'ANNA, 1997, p. 35).
} 
de compaixão, porque todos nós pertencemos a uma história particular, a um mundo que amamos em nossa memória.

Vejamos as semelhanças. Quando a perda parece irremediável:

Joaquim: Meus direitos sobre essas terras não dependem de dívidas. Nasci e fui criado aqui. Aqui nasceram meus filhos. Aqui viveram e morreram meus pais. Isto é mais do que uma simples propriedade. É meu sangue! Não podem me fazer isso.

Liubov Andreievna: (...) Veja, eu nasci aqui, meus pais e também meus avós, todos viveram aqui... Amo esta casa; sem o jardim das cerejeiras a vida não tem sentido para mim, e se for necessário vendê-lo, que me vendam junto com ele.

Quando deixam a fazenda:

Joaquim: (Segundo Plano) (Corta) Está certo, meu filho. Vamos recuperar tudo que é nosso. Tudo! Não tenho a menor dúvida.

(...)

(Joaquim abraşa o relógio, e fica olhando a sala com grande ansiedade)

(...)

(Joaquim volta à sala no Segundo Plano e pega o galho da jabuticabeira que havia esquecido em cima da mesa. Torna a sair, procurando não olhar nada. Depois que Joaquim sai, as lures do Segundo Plano vão diminuindo pouco a pouco até a sala ficar escura).

Liubov Andreievna e Gaiev ficam sozinhos. Como se estivessem esperando apenas por esse momento, lançam-se um nos braços do outro e rompem em soluços, que logo reprimem para não serem ouvidos lá fora.

Gaiev: (desesperado) Minha irmã... Minha querida e boa irmãzinha.

Liubov Andreievna: Oh, meu belo, maravilhoso e querido jardim! Minha vida... minha juventude... Adeus. Adeus!

Ainda que Joaquim saia da fazenda carregando uma esperança de retorno, compreendemos de imediato que essa consiste apenas num escudo para protegê-lo da realidade. Os dois textos se encerram sem que haja qualquer possibilidade de volta. Enquanto ouvimos os sons dos machados a destruir as cerejeiras, 
vemos Joaquim aflito perante o destino do seu amado jabuticabal. As árvores simbolizam um mundo de belezas sendo engolido pela praticidade da nova ordem, que não admite o desperdício, já que elas não têm função econômica dentro das fazendas.

Essa nova ordem surge bem representada por Olímpio, em A moratória, e Lopakhin, em O jardim das cerejeiras. Claro, as diferenças de personalidade são marcantes. Por um lado, Olímpio é um rapaz sensível à mágoa gerada pela repentina e drástica ruptura ocasionada pela mudança da família de sua noiva (que, aliás, ama sinceramente) para a cidade. Nesse sentido, assemelhase mais a Trofimov do que a Lopakhin, já que este, embora visualize um futuro promissor adiante, radiante e novo, não deixa de compreender o sentimento de perda vivenciado pela família de Ânia.

Lopakhin, ao contrário, mostra-se completamente incapaz de se emocionar perante o destino de seus ex-patrões. Sua história de escravidão, porém, justifica plenamente essa frieza, embora não torne, por isso, a personagem mais simpática aos olhos do público. Por outro lado, socialmente, Olímpio exemplifica uma nova e ascendente classe: o profissional liberal, estudado, que virá a formar e dominar futuramente a sociedade urbana que se fortalece. Enquanto Lopakhin se identifica com um mundo capitalista em que a riqueza é apenas transferida para outras mãos, menos elegantes e mais práticas que aquelas dos antigos proprietários rurais.

Ambos indicam uma saída para os problemas financeiros, em momentos determinados das peças. Olímpio, além de se transformar no marido desejado pela família, é o advogado responsável por tentar encontrar alguma brecha que anule o processo de leilão da fazenda. Lopakhin, afora a sugestão infeliz de derrubar e lotear o jardim (sugestão que realizará por conta própria, após a aquisição das terras), é o pretendente de Vária, cujo sonho de casamento esmorece no instante da partida. 
A personagem sugere um caminho prático de sobrevivência, voltado para a especulação imobiliária, caminho esse claramente criticado pelo autor do texto, por meio, exatamente, da falta de sensibilidade de sua criação. Afinal, o descendente de escravos teria tudo para gerar empatia no público, sua vitória sobre os opressores poderia ser comemorada como uma justa vingança dos oprimidos. E ele é, até certo ponto, sedutor. Porém, justamente a falta de compaixão perante a derrocada da família inviabiliza uma identificação da plateia com os seus ideais. O caminho para a libertação não seria esse...

Em $A$ moratória não existe essa sugestão. Não há qualquer demonstração de que a sociedade poderá ganhar algo de determinante, positivo ou negativo, por meio da perda dos privilégios de classe. $\mathrm{O}$ foco do texto não extrapola o universo familiar, restrito; e o desfecho, como enfatizei acima, não oferece qualquer perspectiva de esperança. A comparação entre as peças, aqui, auxilia na constatação de que $A$ Moratória não aponta, sequer indica, qualquer solução para o mundo que retrata. O objetivo primeiro, nessa peça, não é falar sobre a sociedade, mas mostrar um drama familiar que se desenvolve em um contexto social específico. Claro que a temática de $O$ jardim também não é sobretudo social, pelo contrário, daí as semelhanças entre ambas. Porém, existe uma abertura para o social, representada pelo final positivo, onde é possível vislumbrar a esperança da revolução, abertura não encontrada em $A$ moratória.

Portanto, quando lemos, no estudo da professora Elizabeth Azevedo (2001, p. 105), que:

$\mathrm{Na}$ época, apenas um crítico atentou para o assunto: escreveu que era um absurdo ficar lamentando, como se fosse uma tragédia, o fato de termos de trabalhar. Afinal, milhões de pessoas o fazem diariamente. Mas era isso mesmo: a oligarquia chorava o fim de seus privilégios.

É difícil discordar da pesquisadora: esse crítico não entendeu o sentido do texto, seus objetivos, a relevância dos 
sentimentos dos indivíduos para a composição da obra. A peça não fala sobre a mudança na sociedade, sobre a importância de uma distribuição igualitária de trabalho e riquezas. A peça nos fala da perda dos privilégios de uma classe, sim, mas a partir do drama interno de uma família, sem ultrapassar esse limite, sem querer atingir uma macroestrutura épica, capaz de retratar e criticar todo um sistema social, a exemplo da dramaturgia brechtiana. Assim, o texto se mantém restrito na realidade das personagens e o enredo se move a partir do modo como cada membro da família lidou com a perda. Nenhum deles conseguiu aproveitar positivamente, mesmo que de forma parcial, a mudança para a cidade, com tudo que ela carrega.

A resignação de Helena, por exemplo, não pode ser considerada felicidade, tampouco a alternativa de trabalho encontrada por Lucília. O trabalho, para ela, não é uma opção, é um sacrifício, a ponto de pensarmos que a moça está presa àquela casa, aos pais, e que, se eles deixassem de existir ou a situação econômica da família melhorasse, se Quim morresse ou Marcelo assumisse o sustento dos pais, por exemplo, ela poderia se libertar, casar-se, formar sua própria família. Mas Marcelo não tem condições de tomar o lugar da irmã, falta-lhe força: não se habitou ao novo modo de vida e, fraco, esconde-se ou foge das preocupações por meio da bebedeira e da preguiça.

No entanto, é em Quim que a percepção de que "tudo acabou" apresenta-se de maneira mais decisiva. Na cena final, quando descobre que nada mais há para fazer, que tudo está, nas palavras de Décio de Almeida Prado sobre O jardim, citadas no começo desse artigo, "irremediavelmente perdido", ele passa a desfiar fiapos de pano (imagem tirada da memória pessoal do autor, referente a seu avô ${ }^{5}$ ). Ao homem trabalhador do campo, dono de suas terras, nada restou, já que nunca poderá se adaptar a

\footnotetext{
5 "Eu também tenho um avô guardado, não em um jardim de hortênsias, mas entre jabuticabeiras. Também ficava falando sozinho, enquanto desfiava pequeninos trapos que caíam da máquina de costura da minha tia. É o quadro sempre pendurado na minha antesala interior." (ANDRADE apud ARANTES, 2001, p. 22).
} 
uma outra função produtiva, na cidade. Elizabeth Azevedo percebeu essa impossibilidade, a falta de esperança que domina o desfecho da peça, o "herói" Joaquim sucumbe ao seu destino trágico:

\footnotetext{
O resto de sua vida ele será um morto-vivo; o que é, de certa forma, um cadáver exposto.

'Joaquim: Eu... eu não sofro mais, não sofro mais, minha filha. Não precisa ter medo. Eu... eu...'

Poderíamos acrescentar: estou morto!

Essa também é, declaradamente, a visão de Jorge Andrade:

'bem, no final da peça, o personagem começa a desfiar um trapo de pano, mostrando que morreu e, com ele, toda uma classe que não tem mais razão de ser e que não pode voltar mais.' (AZEVEDO, Op. cit., pp-117-8)
}

A vida de Quim, portanto, terminou, ainda que ele continue a respirar. Os anos que lhe restam para viver serão preenchidos por um imenso vazio. Ele não poderá se adaptar, porque está preso a um modo de vida que preencheu suas ações, suas ideias, sua personalidade, durante toda a vida. E os jovens Marcelo e Lucília recebem essa "canga" de herança, por isso também não conseguirão se libertar rumo a um futuro melhor, como o faz, em O jardim das cerejeiras, Ânia, ao receber, com o coração puro, a influência do sonhador Trofimov.

Assim, procurei constatar, por meio dessa análise que gira em torno, principalmente, das personagens, que A moratória, embora remeta, sim, a um momento histórico específico, vai além de uma representação histórica e não apresenta como objetivo discorrer sobre ela. Claro, a peça não deixa de mostrar algo maior sobre o Brasil a partir do drama familiar. No entanto, sua beleza, sua riqueza artística, compreende exatamente o fato de não revelar mais do que um universo centrado nos sentimentos daquelas quatro personagens, tão ricamente trabalhadas. E é por meio dessa caracterização brilhante que esse texto teatral alcança, ao mesmo tempo, dialogar com uma obra culturalmente distante, como $O$ jardim das cerejeiras, e emocionar um espectador que nunca provou goiabada, como um jovem ator norte-americano. 


\section{BIBLIOGRAFIA CITADA:}

ALBISSU, Nelson. Em busca dos velhos de Jorge Andrade no ciclo de Marta. Dissertação de Mestrado. São Paulo, ECA / USP, 1997.

ANDRADE, Jorge. Labirinto. Rio de Janeiro, Paz e Terra, 1978. 1970. , Jorge. Marta, a árvore e o relógio. São Paulo, Perspectiva,

ARANTES, Luiz Humberto Martins, Teatro da memória: história e ficção na dramaturgia de Jorge Andrade. São Paulo, Annablume/Fapesp, 2001.

AZEVEDO. Elizabeth. Recursos estilísticos na obra de Jorge Andrade. Tese de doutoramento. São Paulo, ECA / USP, 2001.

SANT'ANNA, Catarina. Metalinguagem e teatro: a obra de Jorge Andrade. Cuiabá, EdUFMT, 1997.

PRADO, Décio de Almeida. A moratória. In: ANDRADE, Jorge. Marta, a árvore e o relógio. São Paulo, Perspectiva, 1970.

SOUZA NETO, Juvenal de. Jorge Andrade: um autor em busca de si mesmo. Dissertação de mestrado. São Paulo, USP, 1987.

TAKEDA, Cristiane Layher. O cotidiano de uma lenda: cartas do Teatro de Arte de Moscou. São Paulo, Perspectiva, 2003.

Abstract: By means of a character construction analysis of the play A moratoria (1954), by Jorge Andrade (1922-1984), this paper aims to demonstrate how the author explore the themes of Brazilian society urbanization and modernization. For that, I make a comparison with the play The cherry orchard, by Anton Chekhov, and examine the characters divided in generations: Helena and Joaquim (in parallel with Liubov and Gaiev), representing a way of life that is up to its end; and the young Lucília, Marcelo and Olímpio (in parallel with Vária, Ânia, Trofímov and Lopakhin), who try to adapt theirselfs into the urban way of life.

Keywords: playwriting; Jorge Andrade; Anton Chekhov. 